\title{
Profit-Improving Linear Tariffs Pricing in a Vertical Oligopoly
}

\author{
Dong Joon Lee, Sangheon Han, Yuji Ono, Shigetsune Yamoto \\ NUCB Business School, Nagoya University of Commerce and Business, Nagoya, Japan \\ Email: dongjoon@nucba.ac.jp, han-sh@nucba.ac.jp, yujiono@nucba.ac.jp, yamoto@nucba.ac.jp
}

How to cite this paper: Lee, D.J., Han, S., Ono, Y. and Yamoto, S. (2018) Profit-Improving Linear Tariffs Pricing in a Vertical Oligopoly. Theoretical Economics Letters, 8, 2055-2062. https://doi.org/10.4236/tel.2018.811134

Received: June 6, 2018

Accepted: July 29, 2018

Published: August 2, 2018

Copyright $\odot 2018$ by authors and Scientific Research Publishing Inc. This work is licensed under the Creative Commons Attribution International License (CC BY 4.0).

http://creativecommons.org/licenses/by/4.0/

\section{cc) (i) Open Access}

\begin{abstract}
Considering the interplay between intra-firms (own retailing firms) and inter-firms (rival retailing firms) competition in vertically related markets, we compare linear tariffs and two-part tariffs pricing. In contrast to previous results, we show that when both products are sufficiently close substitutes, there is a threshold level of the number of retailing firms, beyond which each manufacturing firm's profits are larger under linear tariffs pricing than under two-part tariffs pricing. It shows the contradictions to the conventional wisdom that two-part tariffs pricing is always better than linear tariffs pricing from the viewpoint of manufacturing firms. We also show that the wholesale prices increase as the number of retailing firms increases under two-part tariffs pricing, regardless of the degree of product substitutability.
\end{abstract}

\section{Keywords}

Linear Tariffs Pricing, Two-Part Tariffs Pricing, Double Marginalization, Competition

\section{Introduction}

Traditionally, a pricing inefficiency in vertically related markets is caused by double marginalization problem ${ }^{1}$. While the distortion is the most pronounced in successive monopoly, the basic insight remains relevant under imperfect competition. In the majority of markets, manufacturing firms sell the products to its independent retailers who sell them to consumers. A conventional wisdom is that the double marginalization problem can be avoided through two-part tariffs contract which consists of a wholesale price per unit and a fixed fee ${ }^{2}$. To put it another way, the use of more instruments enable manufacturing firms to lead ${ }^{1}$ Spengler [1] firstly addressed the double margin distortion.

${ }^{2}$ For two-part tariffs pricing, see Rey and Tirole [2], Rey and Stiglitz [3] [4], Bonanno and Vickers [5], Saggi and Vettas [6] and so on. 
higher profits. However, in reality, we often find that manufacturing firms do not use two-part tariffs contract, even though they can implement two-part tariffs contract ${ }^{3}$. For example, we usually see the linear tariffs pricing in the transactions between manufacturers and retailers relevant to convenience goods, such as grocery, foods, gasoline and so on. The aim of this paper is to examine the conventional wisdom that the profits of manufacturing firms are higher under two-part tariffs pricing than under linear tariffs pricing in vertically related markets.

Imperfect control of retail prices gives rise to the double marginalization distortion (Spengler [1]). The lack of control of selling costs may give rise to under-investments and free-riding (Telser [9]). To cite well-developed papers, two-part tariffs contract or resale price maintenance can solve double marginalization. Mathewson and Winter [10] [11] offer a fairly comprehensive treatment of these types of control. This paper is an interesting and intuitive explanation of the above mentioned real world example. We find that vertical restraints may or may not be desirable of the manufacturers' point of view. Generally speaking, in a vertically related market with a manufacturer and a retailer in which wholesale price is the monopoly price set by the manufacturer and then the retail price is above the monopoly price. From the viewpoint of manufacturer, retail prices are higher than in the market with an integrated firm. So, its profit will be reduced in the vertical structure. The distortion persists even in vertical oligopoly. Theoretically, it can be solved through the use of more sophisticated contracts. For example, there are a profit-sharing contract, two-part tariffs contract, resale price maintenance with exclusive territories, and so on. Without the sophisticated contracts, the double marginalization distortion can be avoided by vertical integration. Bonanno \& Vicker [5] show that manufacturers have an incentive to sell their products through their exclusive retailers so as to soften retailing competition. As a similar result, Rey and Stiglitz [4] show how vertical restraints can and will be used for reducing inter-brand competition.

Focusing on a vertical structure, we compare linear tariff pricing to two-part tariffs pricing. We consider the interplay between intra-firms (own retailing firms) and inter-firms (rival retailing firms) competition in vertically related markets. In contrast to conventional wisdom that the more strategic variable, the more profits, we show that when both products are sufficiently close substitutes, there is a threshold level of the number of downstream firms, beyond which each upstream firm's profits are larger under linear tariffs pricing than under two-part tariffs pricing. Our results show the contradictions to the conventional wisdom that two-part tariffs pricing is better than linear tariffs pricing from the viewpoint of manufacturing firms. We also show that the wholesale prices increase as the number of downstream firms increases under two-part tariffs pricing, regardless of the degree of product substitutability.

The remainder of the paper is organized as follows. In Section 2, we set up the ${ }^{3}$ See Lafontaine [7] and Lafontaine and Slade [8] for details. 
model. Section 3 examines linear tariffs and two-part tariffs pricing. Section 4 presents the main results. Finally, Section 5 provides the concluding remarks.

\section{The Model}

Consider two identical manufacturing firms. Each manufacturing firm sells its product to its exclusive retailing firms. For each manufacturing firm,

$i, j=1,2, i \neq j$, let $(i) n\{(i) 1,(i) 2, \cdots,(i) n-1,(i) n\}, n \geq 2$, be the set of exclusively independent retailing firms. The indirect demand function is as follows:

$$
p_{i}=a-Q_{i}-d Q_{j}, i, j=1,2, i \neq j,
$$

where $p_{i}$ denotes the output price, $Q_{i}=\sum q_{i n}$ and $Q_{j}=\sum q_{j n}$ denote, respectively, the aggregate output of each manufacturing firm who sells product $i$ and $j$. The parameter $d \in(0,1)$ denotes the degree of product differentiation. As the parameter $d$ approaches zero, both products become more differentiated, and as the parameter $d$ approaches one, both products become less differentiated. The marginal cost for each manufacturing firm is simply $c$. For simplicity, there are no retailing cost.

We posit a two-stage game. At stage one, each manufacturing firm offers either a linear tariffs or two-part tariffs pricing to its exclusive retailing firms. Two-part tariffs pricing is composed of two parameters: wholesale price w and fixed fee $f$. Without loss of generality, we assume that the same contract is offered to all downstream firms. At stage two, each retailing firm sets the output. We solve a sub-game perfect Nash equilibrium (SPNE) through backward induction.

\section{Analysis}

We first consider the case in which each manufacturing firm proposes a linear tariffs pricing to its retailing firms. At stage two, retailing firm in chooses its outputs $q_{\text {in }}$ so as to maximize its profits for given all other retailing firms' outputs and wholesale price $w_{i}$. Retailing firm ik's maximization problem is as follows:

$$
\max \pi_{i n}=\left(p_{i}-w_{i}\right) q_{i n}=\left(a-w_{i}-Q_{i}-d Q_{j}\right) q_{i n}, \text { w.r.t. } q_{i n} .
$$

Differentiating the maximization problem with respect to $q_{i n}$, we obtain the first-order conditions as follows:

$$
q_{i n}=\frac{a-w_{i}-Q(i-i n)-d Q_{j}}{2}, i, j=1,2, i \neq j, n=1,2, \cdots, n-1, n,
$$

where $Q(i-i n)=Q_{i}-q_{\text {in }}$.

Aggregating and Solving Equation (2), we obtain the equilibrium total outputs in terms of the wholesale prices $\left(w_{i}, w_{j}\right)$ as follows:

$$
Q_{i}=\frac{n\left[(1-d) n+1 a-(n+1) w_{i}+d n w_{j}\right]}{[(1+d) n+1][(1-d) n+1]}, i, j=1,2, i \neq j .
$$

At stage one, manufacturing firm $i$ sets its wholesale prices $w_{i}$ so as to 
maximize its profits for a given rival's wholesale prices $w_{j}$. Its maximization problem is as follows:

$$
\max \Pi_{i}=\left(w_{i}-c\right) Q_{i}=\left(w_{i}-c\right) \frac{n\left[\{(1-d) n+1\} a-(n+1) w_{i}+d n w_{j}\right]}{[(1+d) n+1][(1-d) n+1]}, \text { w.r.t. } w_{i} .
$$

Differentiating the maximization problem with respect to $w_{i}$, we obtain the first-order conditions as follows:

$$
w_{i}=\frac{\{(1-d) n+1\} a+(n+1) c+d n w_{j}}{2(n+1)}, i, j=1,2, i \neq j .
$$

Note that $w_{i}$ and $w_{j}$ under linear tariffs pricing are strategic complements. From Equation (4), we obtain the equilibrium wholesale prices as follows:

$$
w_{i}^{L}=w_{j}^{L}=c+\frac{\{(1-d) n+1\}(a-c)}{(2-d) n+2},
$$

where the superscript " $\mathrm{"} \mathrm{denotes} \mathrm{linear} \mathrm{tariffs} \mathrm{pricing.}$

Finally, we obtain the equilibrium total outputs, prices, each retailing and manufacturing firm's profits as follows:

$$
\begin{gathered}
Q_{i}^{L}=Q_{j}^{L}=\frac{n(n+1)(a-c)}{\{(2-d) n+2\}\{(1+d) n+1\}}, \\
p_{i}^{L}=p_{j}^{L}=c+\frac{\left[(1+d)(1-d) n^{2}+3 n+2\right](a-c)}{\{(2-d) n+2\}\{(1+d) n+1\}}, \\
\pi_{i}^{L}=\pi_{j}^{L}=\frac{(n+1)^{2}(a-c)^{2}}{\{(2-d) n+2\}^{2}\{(1+d) n+1\}}, \\
\Pi_{i}^{L}=\Pi_{j}^{L}=\frac{n(n+1)(1-d) n+1(a-c)^{2}}{\{(2-d) n+2\}^{2}\{(1+d) n+1\}} .
\end{gathered}
$$

We next turn to a case in which each manufacturing firm proposes a two-part tariffs pricing to its retailing firms. Note that the fixed fees do not affect the output decision of each retailing firm. So, at stage two, we obtain the same results as obtained in the linear tariffs pricing. At stage one, manufacturing firm $i$ sets the wholesale price $w_{i}$ and the fixed fees $\left(f_{i 1}, f_{i 2}, \cdots, f_{i(n-1)}, f_{i n}\right)$ so as to maximize its profit for a given rival's wholesale price $w_{j}$. Its maximization problem is as follows:

$$
\begin{aligned}
& \max \Pi_{i}=\left(w_{i}-c\right) Q_{i}+F_{i} \\
& \qquad=\left(w_{i}-c\right) \frac{n\left[(1-d) n+1 a-(n+1) w_{i}+d n w_{j}\right]}{[(1+d) n+1][(1-d) n+1]}+F_{i}, \\
& \text { w.r.t. } w_{i} \text { and } F_{i}, \\
& \text { s.t. } \sum\left(p_{i}-w_{i}\right) q_{i} n-f_{i} n \geq 0,
\end{aligned}
$$

where $F_{i}=\sum f_{i n}$. Note that the above constraint conditions are binding. So, we can rewrite manufacturing firm $i$ s maximization problem as follows: 


$$
\begin{aligned}
\max \Pi_{i}= & \left(p_{i}-c\right) Q_{i} \\
= & \left(\frac{\{(1-d) n+1\} a+\{(1+d)(1-d) n+1\} n w_{i}+d n w_{j}}{[(1+d) n+1][(1-d) n+1]}-c\right) \\
& \times \frac{n\left[(1-d) n+1 a-(n+1) w_{i}+d n w_{j}\right]}{[(1+d) n+1][(1-d) n+1]}, \quad \text { w.r.t. } w_{i}
\end{aligned}
$$

Differentiating the maximization problem with respect to $w_{i}$, we obtain the first-order conditions as follows:

$$
\begin{aligned}
w_{i}= & \frac{[(1-d) n+1]\left[\left\{(1+d)(1-d) n^{2}-1\right\} a+(n+1)\{(1+d) n+1\} c\right]}{2 n(n+1)[(1+d)(1-d) n+1]} \\
& -\frac{d\left[(1+d)(1-d) n^{2}-1\right] w_{j}}{2 n(n+1)[(1+d)(1-d) n+1]}, i, j=1,2, i \neq j .
\end{aligned}
$$

Note, under two-part tariffs pricing, $w_{i}$ and $w_{j}$ strategic substitutes if $n<n^{*}, w_{i}$ and $w_{j}$ strategic complements if $n \geq n^{*}$, where $n^{*}=\frac{\sqrt{1-d^{2}}}{1-d^{2}}$.

From Equation (10), we obtain the equilibrium wholesale prices as follows:

$$
w_{i}^{T}=w_{j}^{T}=c+\frac{\left[(1+d)(1-d) n^{2}-1\right](a-c)}{[(2-d)(1+d) n+(2+d)] n},
$$

where the superscript " $T$ " denotes two-part tariffs pricing.

Notice that each manufacturer sets its wholesale prices below marginal production costs if $n<n^{*}$.

Finally, we obtain the equilibrium total outputs, prices, each retailing and manufacturing firm's profits as follows:

$$
\begin{gathered}
Q_{i}^{T}=Q_{j}^{T}=\frac{(n+1)(a-c)}{(2+d)+(1+d)(2-d) n}, \\
p_{i}^{T}=p_{j}^{T}=c+\frac{(1+d)(1-d) n+1(a-c)}{(2+d)+(1+d)(2-d) n}, \\
\Pi_{i}^{T}=\Pi_{j}^{T}=\frac{\{(1+d)(1-d) n+1\}(a-c)^{2}}{[(2+d)+(1+d)(2-d) n]^{2}} .
\end{gathered}
$$

\section{Results}

In the previous section, we analyzed the linear tariffs and two-part tariffs pricing in a vertically related oligopolistic market. In this section, we compare the equilibrium outcomes between two pricings. From Equation (11), we obtain the following results.

$$
w^{T} \geq c \text { if } n \geq \frac{\sqrt{1-d^{2}}}{1-d^{2}}=n^{*} .
$$

The interval of the equilibrium wholesale prices under two-part tariffs pricing 
over parameter space $\{n, d\}$ is drawn in Figure 1 .

Traditionally, each manufacturing firm sets its wholesale prices below its marginal costs under Cournot competition with franchise fee. The intuition behind the results is that $a(n)$ below or above wholesale prices may be used in two-part tariffs pricing. It depends on the magnitude between the incentive to soften the competition among its own retailing firms and the incentive to obtain a strong position against rival retailing firms. When the latter effect is overwhelmed by the former effect, each manufacturing firm sets the wholesale prices above marginal cost.

Differentiating Equation (5) and Equation (11) with respect to the number of retailing firms $(\mathrm{n})$, we obtain the following results:

$$
\begin{gathered}
\frac{\partial w^{L}}{\partial n}=-\frac{d(a-c)}{(2+(2-d) n)}<0, \\
\frac{\partial w^{T}}{\partial n}=-\frac{2+d+2(2-d)(1+d) n+\left\{(1-d)(1+d)(2+d) n^{2}\right\}(a-c)}{\left[\{2+d+(1+d)(2-d) n\} n^{2}\right]^{2}}>0 .
\end{gathered}
$$

These results are summarized in Proposition 1.

Proposition 1. The equilibrium wholesale prices $\left(w^{T}\right)$ under two-part tariffs pricing increase as the number of retailing firms $(n)$ increases, while the equilibrium wholesale prices $\left(w^{L}\right)$ under linear tariffs pricing decrease as the number of retailing firms $(n)$ increases.

Explain the Proposition 1's Intuition.

Finally, we compare the profits. From Equation (9) and Equation (14), we obtain the following results:

$$
\Pi^{L}>\Pi^{T} \text { if } n<\frac{8}{\left(4+5 d+\sqrt{16-8 d+25 d^{2}}\right) d-8}=n^{* *}
$$

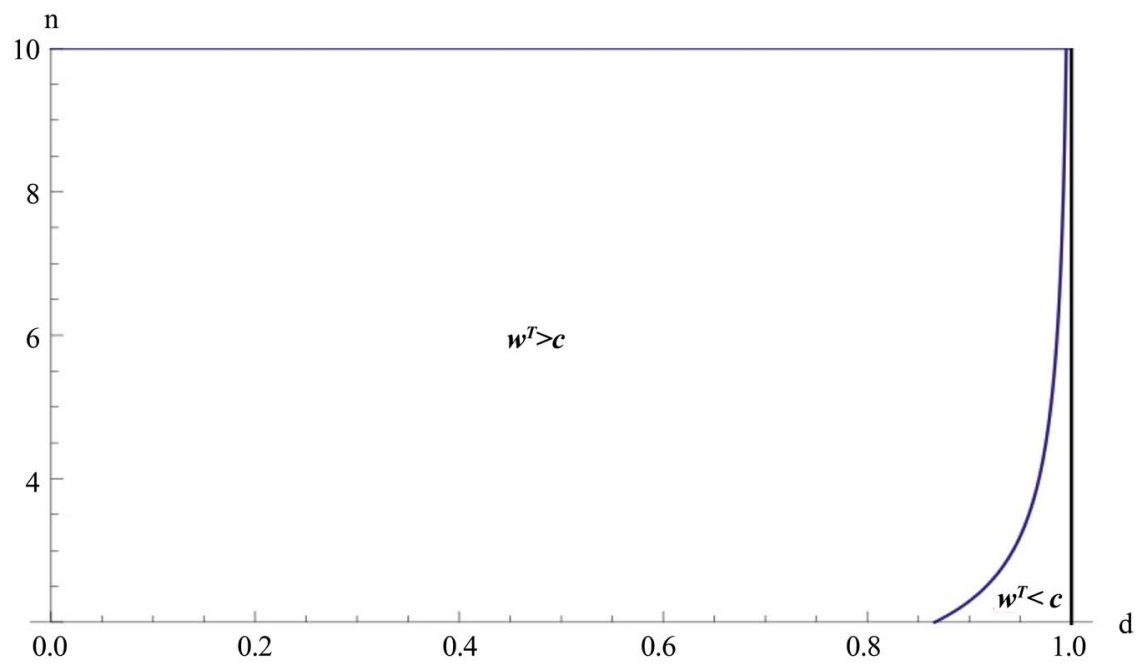

Figure 1. Wholesale prices under two-part tariffs pricing. 
The comparison of $\Pi^{L}$ and $\Pi^{T}$ over parameter space $\{n, d\}$ is drawn in Figure 2.

These results are summarized in Proposition 2.

Proposition 2. When both products are sufficiently close substitutes, there is a threshold level of the number of retailing firms $(n)$, beyond which manufacturing firms' profits are higher under linear tariffs pricing than under two-part tariffs pricing.

Proposition 2 can be explained as follows. We suppose Cournot competition in vertical oligopoly. Two-part tariffs pricing has the advantage of eliminating double margin distortion, but has the disadvantage of inducing fierce competition between retailing firms. In Cournot competition, manufacturers set the wholesale prices below its marginal cost in order to avoid the double margin distortion. It induces retailing firms to intensify the competition. On the other hand, linear tariff pricing has the advantage of softening retailing competition, but disadvantage of persisting double margin distortion. Under these circumstances, the number of retailing firms $(n)$ and the degree of product substitutability ( $d$ ) play important roles in manufacturers' profits. We suppose that retailing market is sufficiently competitive when the number of retailing firms $(n)$ is sufficiently large and the degree of product substitutability (d) approaches to 1 . In this case, manufacturers use linear tariff pricing in order to soften retailing competition rather than to avoid double margin distortion Therefore, we obtain the proposition 2 .

\section{Concluding Remarks}

This paper compares upstream firms' profits between linear tariff and two-part tariffs pricing in a vertically related market where both intra-firm (own retailing firms) and inter-firm (rival retailing firms) competition are present. The basic intuition is as follows. From the standpoint of manufacturing firms, above wholesale prices have the advantage of softening the competition among their

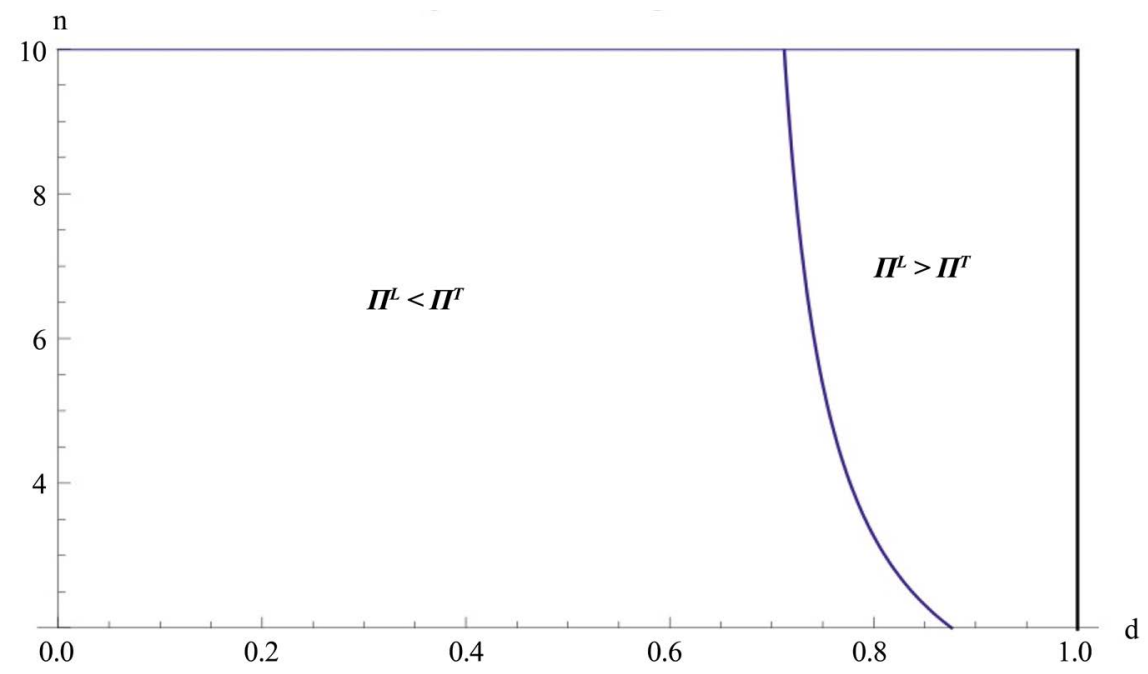

Figure 2. Wholesale prices under two-part tariffs pricing. 
own retailing firms, but have disadvantage of being an inferior position against their rival retailing firms in competition. On the other hand, below wholesale prices have the advantage of strengthening the competition against their rival retailing firms, but have the disadvantage of strengthening the competition among their own retailing firms. Our main results are two. One is that when the number of downstream firms increases, the equilibrium wholesale prices increase under two-part tariffs pricing, regardless of the degree of product differentiation. Another is that manufacturing firms' profits are higher under linear tariff pricing than under two-part tariffs pricing when both products are sufficiently close substitutes and the number of retailing firms are also sufficiently large.

We conclude by discussing the limitations. We focused on the linear demand function in a vertical structure. For further research, it will be interesting to investigate whether our results will hold with non-linear demand as well. It will also be interesting to study what would happen if vertically integrated and separated distribution channels coexist. The extension of our model in these directions has been left for future research.

\section{Funding}

This research is supported by Japan Society for Promotion of Science, Grant-in-Aid, for grant number18K01896.

\section{References}

[1] Spengler, J. (1950) Vertical Integration and Antitrust Policy. Journal of Political Economy, 58, 347-352.

[2] Rey, P. and Tirole, J. (1986) The Logic of Vertical Restraints. American Economic Review, 76, 921-939.

[3] Rey, P. and Stiglitz, J. (1988) Vertical Restraints and Producers' Competition. European Economic Journal, 32, 561-588.

[4] Rey, P. and Stiglitz, J. (1995) The Role of Exclusive Territories in Producers' Competition. RAND Journal Economics, 26, 431-451. https://doi.org/10.2307/2555997

[5] Bonanno, G. and Vickers, J. (1988) Vertical Separation. Journal of Industrial Economics, 36, 257-265. https://doi.org/10.2307/2098466

[6] Saggi, K. and Vettas, N. (2002) On Intra-Brand and Inter-Brand Competition: The Strategic Role of Fees and Royalties. European Economic Journal, 46, 86-105.

[7] Lafontaine, F. (1992) Agency Theory and Franching: Some Emperical Results. RAND Journal Economics, 23, 263-283. https://doi.org/10.2307/2555988

[8] Lafontaine, F. and Slade (1997) Retailing Contracting: Theory and Practice. Journal of Industrial Economics, 45, 1-25. https://doi.org/10.1111/1467-6451.00032

[9] Telser, L. (1960) Why Should Manufacturers want Fair Trade. Journal of Law and Economics, 3, 86-105. https://doi.org/10.1086/466564

[10] Mathewson, G. and Winter, R. (1983) The Economics of Vertical Restraints in Distribution. New Developments in the Analysis of Market Structure, 211-239.

[11] Mathewson, G. and Winter, R. (1984) An Economic Theory of Vertical Restraints. Rand Journal of Economics, 15, 27-38. https://doi.org/10.2307/3003667 